\title{
Modelling colour and chlorophyll losses of frozen green beans (Phaseolus vulgaris, L.)
}

\author{
R.C. Martins, C.L.M. Silva* \\ Escola Superior de Biotecnologia, Universidade Católica Portuguesa, Rua Dr. António Bernardino de Almeida, \\ 4200-072 Porto, Portugal
}

\begin{abstract}
Colour changes and chlorophyll degradation of frozen green beans (Phaseolus vulgaris, L., variety bencanta) were studied during 250 days of storage at $-7,-15$ and $-30{ }^{\circ} \mathrm{C}$. Chlorophyll a and $\mathrm{b}$ losses and colour Hunter $a$ and $b$ coordinates and total colour difference $\left(\mathrm{TCD}_{\mathrm{H}}\right)$ changes were successfully described by first order and reversible first order models, respectively. The temperature effect was described by the Arrhenius law. Disagreement between the colour co-ordinates and chlorophyll content was obtained. Therefore, chlorophyll content is not a good colour index of frozen green beans. The results emphasise that colour is a more important parameter to assess frozen green beans visual quality.
\end{abstract}

Keywords: Vegetable; Green bean; Frozen food; Chlorophyll; Colour; Measurement; Modelling

\section{Haricots verts congelés : modélisation de la diminution de l'intensité de la couleur et de la teneur en chlorophylle}

Mots clés : Légume ; Haricot vert ; Produit congelé ; Chlorophylle ; Couleur ; Mesure ; Modélisation

\section{Introduction}

Green Beans (Phaseolus vulgaris, L.) is a Leguminosae produced in considerable volumes in Portugal. The outdoor varieties are generally produced all over the country seasonally, and are excellent in both nutritional value (e.g. high content in vitamins, fibber and starch) and in quality parameters such as colour, texture, aroma and flavour. Consequently, they are very important products in both dietary and economical terms for the Portuguese community.

* Corresponding author. Tel.: +351-22-5580058; fax: +351-22-5090351.

E-mail addresses: crislui@esb.ucp.pt (C.L.M. Silva), rmcm@morango.esb.ucp.pt (R.C. Martins).
Although frozen storage is well known for its excellence in preserving vegetable quality, significant colour and chlorophyll losses occur to green vegetables during storage [1-3].

Colour loss during frozen storage is attributed to the fading of the vivid green colour of chlorophyll to an olive brown, characteristic of pheophytin [4-11]. This phenomena is known as pheophytisation, where the centre magnesium is replaced by hydrogen. Another common type of deterioration, is the removal of the phytol chain, leading to the formation of chlorophyllide (removal from chlorophyll) or pheophorbide (removal from pheophytin). Furthermore, reactions related with the functional side groups of chlorophyll form colourless end products, that also affect colour during frozen storage (e.g. the isocyclic ring may be oxidised to form 


\section{Nomenclature}

$C \quad$ Quality at time $t$ (Hunter colour co-ordinates or chlorophyll content)

$T \quad$ Absolute storage temperature, $\mathrm{K}$

$k \quad$ Kinetic rate, day $^{-1}$

$E_{\mathrm{a}} \quad$ Arrhenius activation energy, $\mathrm{J} \mathrm{mol}^{-1}$

$R \quad$ Universal gas constant, $\mathrm{J} \mathrm{mol}^{-1} \mathrm{~K}^{-1}$

$L \quad$ Hunter colour space co-ordinate: degree of Lightness

a Hunter colour space co-ordinate: ratio of red/green

$b \quad$ Hunter colour space co-ordinate: ratio of blue/yellow

TCD Total colour difference

SE Regression standard error

\section{Subscripts}

$0 \quad$ Refers to the initial quality content, at storage time zero

eq Refers to the equilibrium quality content

$\mathrm{H}$ Refers to the Hunter colour space

ref At the reference temperature

allomerised chlorophyll). Because pheophytisation reaction rates are generally higher than other chlorophyll degradation pathways [12], it is considered the most important mechanism of chlorophyll destruction during food processing.

During frozen storage, the low storage temperatures enhance low protein foods' tendency to exhibit $\mathrm{pH}$ decrease (e.g. milk, green beans) $[13,14]$, increasing acid catalysed reactions rates [15], such as pheophytisation.

Residual enzymatic activity, due to inadequate blanching treatment, is also a probable cause of chlorophyll loss. For example, Lipoxigenase activity on free fatty acids may increase pheophytisation rate, due to the increase in $\mathrm{H}^{+}$concentration [9].

Although most enzymes can be well preserved by frozen storage, enzyme activity is limited by storage temperature, due to physical and chemical changes in the unfrozen phase. Furthermore, if adequate blanching treatment is applied, enzyme activity during frozen storage can be negligible when compared to colour and of chlorophyll's chemical degradation.

As expected, the major pathway of degradation of chlorophyll is by direct or indirect pheophytisation to pheophytins. Therefore, in mechanistic terms, this process can be represented by a first order reaction kinetics, following Arrhenius behaviour with the storage temperature [16]:
$\frac{C}{C_{0}}=\exp \left(-k_{\text {ref }} \cdot \mathrm{e}^{-\frac{E_{\mathrm{a}}}{R}\left[\frac{1}{T}-\frac{1}{T_{\text {ref }}}\right]} \cdot t\right)$

where $C$ is the concentration of chlorophyll a or $\mathrm{b}$ at time $t, C_{0}$ is the initial concentration, $k_{\text {ref }}$ the kinetic rate at the absolute reference temperature $T_{\text {ref }}, T$ is the absolute temperature, $R$ the universal gas constant and Ea the Arrhenius activation energy. This kinetic model was previously applied and verified during thermal processing [6-8].

Chlorophyll content has not been shown to predict accurately the colour index of frozen green beans. Therefore, direct colour measurement is necessary to describe accurately colour evolution during storage.

Light projected on the surface of a vegetable results in specular reflectance, diffuse reflectance to a depth of 5 $\mathrm{mm}$, and diffuse transmittance [17]. However, colour perception is not only associated with spectral reflectance, but also with appearance, texture and other sensory interpretations of the visual aspects of foods $[18,19]$.

Several colour systems have been developed for colorimeter measurement, where all are mathematically convertible [20-23]. However, the Hunter Lab colour space has been preferred to characterise colour loss in fruits and vegetables, due to its simplicity in the interpretation of changes in colour co-ordinates.

Colour changes can be measured as the modulus of the distance vector between the initial colour values, $L_{0} a_{0} b_{0}$, and the actual colour co-ordinates. This concept is named total colour difference or colour difference $[20,22,24]$ :

$\operatorname{TCD}_{\mathrm{H}}=\left[\left(L-L_{0}\right)^{2}+\left(a-a_{0}\right)^{2}+\left(b-b_{0}\right)^{2}\right]^{1 / 2}$

Colour changes in green vegetables were previously modelled by Steet and Tong [11] for the pheophytisation of pureed green peas during thermal treatment. They also modelled the evolution of $a$ with storage time using a first order reversible kinetics (or fractional) model:

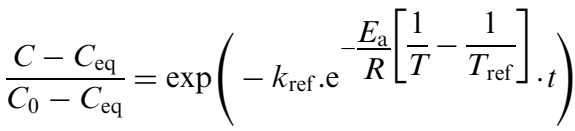

where $C$ is the $a$ at time $t, C_{0}$ the starting value of $a, C_{\mathrm{eq}}$ is the $a$ at infinite storage time, when all chlorophyll is converted into pheophytin, and $k_{\text {ref }}$ the kinetic rate at the reference temperature. This model assumes that the initial and final colour coordinates are not dependent on the storage temperature, and vary within the range colour change only due to pheophytisation. This approach has also been successfully applied to the Hunter Lab and CIE $L^{*} a^{*} b^{*}$ systems to model the colour changes during thermal processes $[25,26]$. 
Chlorophyll and colour losses of frozen vegetables were firstly studied using the time temperature tolerance studies (TTT) [2,3]. These early studies were focused on the characterisation of frozen storage quality losses and shelf life determination of frozen foods [27], rather than obtaining quality degradation kinetics.

Arrhenius behaviour with storage temperature has been assumed in most kinetic studies, but it may not be applicable during low storage temperatures. If solutes concentration occurs in the unfrozen phase and the storage temperature is near the maximum freeze concentration and glass transition temperature $\left(T_{\mathrm{g}}{ }^{\prime}\right)$, kinetics may not follow the Arrhenius law, due to a sudden decrease in solutes molecular mobility. This issue is particularly pertinent to frozen foods quality loss modelling.

There has been few kinetic studies in the field of frozen foods storage, especially in fruit and vegetables. Therefore, the main objectives of this research were to:

1. evaluate how colour and chlorophyll losses occur during long term frozen storage of green beans

2. obtain the reaction kinetics

3. investigate the applicability of the Arrhenius law

4. investigate the relationship between chlorophyll content and Hunter Lab coordinates

5. determine if chlorophyll content is a good predictor of colour quality index during storage.

\section{Materials and methods}

\subsection{Sample preparation}

Green beans (Phaseolus vulgaris, L.) were obtained from Porto local city market, Portugal, 1 day after harvesting. They were firstly sorted, washed and blanched in water $\left(2 \mathrm{~min}\right.$ at $\left.100^{\circ} \mathrm{C}\right)$. After blanching, green beans were left to cool and dry, and were then frozen in a blast freezer, Armfield FT 36, (Armfield, 1995 [28]). Samples were frozen at an average air temperature of $-40{ }^{\circ} \mathrm{C}$, until the temperature of $-35{ }^{\circ} \mathrm{C}$ was recorded with a thermocouple placed in the centre of a green bean test sample. Approximately $500 \mathrm{~g}$ of frozen green beans were immediately put into polyethylene bags $(35 \times 22 \mathrm{~cm})$ and heat sealed. Packed green beans were stored in three laboratory refrigerators (Fitotherm, model S550 BT) at storage temperatures of $-7,-15$ and $-30{ }^{\circ} \mathrm{C} \pm 1{ }^{\circ} \mathrm{C}$. The samples were analysed over a period of 250 days and sampled randomly from different locations in the freezer.

\subsection{Peroxidase activity}

Peroxidase activity determination was used as a control test of the effectiveness of the blanching treatment, and to check if any peroxidase regeneration occurred during long term frozen storage. Peroxidase activity was determined by a spectrophotometer assay adapted from Barth et al. (1993) [29] and Hemeda and Kliend (1990) [30].

\section{3. pH measurement}

The $\mathrm{pH}$ was determined using an adaptation of Eheart and Gott (1965) [31] method, where $50 \mathrm{~g}$ of green beans and $100 \mathrm{ml}$ of distilled water were mixed and ground for $3 \mathrm{~min}$ with a mixer (Moulinex, France). Thereafter, $\mathrm{pH}$ determinations were monitored after 2 min with a glass electrode $\mathrm{pH}$ meter (microph 2001, Crison Instruments S. A., Spain). The initial pH was measured for fresh, blanched, and frozen green beans with three replicates. Thereafter, $\mathrm{pH}$ measurements were made monthly.

\subsection{Chlorophyll measurement}

Samples were collected at 5 day intervals, and the first measurements were made before and immediately after freezing. Green beans were chopped and ground while frozen into small pieces, as a preparation for pigment extraction. A spectophotometric procedure developed by Vernon (1960) [32] was used to quantify chlorophyll $\mathrm{a}$ and $\mathrm{b}$ and pheophytin $\mathrm{a}$ and $\mathrm{b}$. The specimen concentrations were measured with three replicates for each storage temperature.

\subsection{Colour measurement}

Samples were collected at 5 day intervals. The first measurements were made immediately before and after freezing. The Hunter $L a b$ co-ordinates were measured by a tristimulus colorimeter (model CR300, Minolta Corporation, Japan). The colorimeter was calibrated with a standard white tile $(Y=95.3, x=0.3133, y=$ 0.3197). Green beans were thawed and cut into small rectangles, and thereafter, placed on the platform of the colorimeter. Measurements were made with ten replicates for each storage temperature.

\subsection{Statistical analysis}

The ANOVA one factor test with replication $(\alpha=0.05)$ was performed to determine if there were significant differences in terms of colour or chlorophyll content due to blanching treatment and freezing. Nonlinear regression analysis for model fitting was performed on all data, in a one-step optimisation procedure [33], by maximising the likelihood function for all the three temperatures. The kinetic parameters of Eqs. (2) and (3) were estimated for chlorophyll's and colour losses, respectively. A computer program was developed in Matlab 4.0 (The MathWorks Inc., 1993), using the Gauss-Newton optimisation algorithm to solve the nor- 
mal equations and determine the parameters estimates. The estimated parameter's variance was obtained by the variance-covariance matrix of the regression coefficients and the model standard deviation was estimated by the mean standard error $[34,35]$. The studentised effect $\left(\beta_{i} /\right.$ $s\left\{\beta_{i}\right\}$ ) of each kinetic parameter was computed to define the importance at a 5\% confidence level (double sided $T$-test). The semi studentised residuals were examined for outlayers, randomness and tested for normality [36] to assess the quality of the fitted kinetic models.

\section{Results and discussion}

Peroxidase activity was not detected at the three studied storage temperatures. Therefore, the probability of enzymatic activity affecting both colour and/or chlorophyll losses is very low. The $\mathrm{pH}$ decreased until the 20th day of storage, from an initial value of $6.32 \pm 0.12$ until $5.48 \pm 0.27$. Thereafter, $\mathrm{pH}$ did not changed significantly $(P>0.05)$. Thus, $\mathrm{pH}$ decrease of frozen green beans due to the freezing process was verified. However, the extent of the $\mathrm{pH}$ decrease in frozen stored green beans is still unknown.

\subsection{Chlorophyll $a$ and $b$ losses}

The blanching treatment and freezing did not change significantly the initial chlorophyll content or colour $(P>0.05)$. Also, as expected, green beans exhibit an initial higher content of chlorophyll a than chlorophyll b. The low variability in chlorophyll content was due to the mixing of different green beans samples while doing chlorophyll extraction. Chlorophyll $\mathrm{a}$ and $\mathrm{b}$ and total chlorophyll degradation were observed during the 250 days of frozen storage for the three studied temperatures.

The degradation of both chlorophyll $a$ and $b$ followed a first order reaction kinetics with an Arrhenius behaviour with storage temperature, exhibiting a good correlation coefficient between the fitted model and experimental data (Table 1). No differences were obtained between the degradation rates of chlorophyll a and $b$, as was previously reported during thermal treatment experiments [6-8]. Because of the low variation in chlorophyll a and b content, low variation and collinearity between the estimated kinetic parameters was obtained, leading to excellent precision in both kinetic rate at the reference temperature and Arrhenius activation energies (Table 1). Total chlorophyll content (Fig. 1), obtained by the addition of the two chlorophyll concentrations, exhibited a good correlation coefficient (0.9609), and, as expected, a low model variance $(4.3646 \mathrm{E}-3 \mathrm{mg} / \mathrm{g})$. The high scores of the studentised effect of the kinetic parameters $C_{0}, k_{-15}{ }^{\circ} \mathrm{C}$, and $E_{\mathrm{a}}$ $\left(t\left(\beta_{i}\right)>t_{(1-\alpha / 2 ;}\right.$ df $)$, emphasise that all parameters are important to describe chlorophyll loss during storage. Furthermore, they demonstrate the applicability of the Ahrrenius law. The high activation energy of chlorophyll degradation, enables frozen storage to kinetically constrain the pigment destruction, which makes frozen storage at low temperatures a good mean of preserving chlorophyll. However, the high activation energy also makes this quality parameter very sensitive to higher storage temperatures and temperature fluctuations inside freezers.

\subsection{Colour changes}

Colour differences were perceptible to the human eye between green bean samples, stored at different temperatures, since the first measurement. The initial $\mathrm{TCD}_{\mathrm{H}}$ value was $3.74 \pm 0.10$ [20]. Colour losses occurred at significant fast rates at the storage temperatures of -7 and $-15{ }^{\circ} \mathrm{C}$, attaining great colour differences after 15 and 30 days of storage time, respectively. The recorded Hunter $L$ value described a random pattern behaviour, around an average value of $38.0 \pm 3.8$, and, therefore, it did not change significantly $(P>0.05)$. The high biological variability in colour of green beans can be visualised in Fig. 2. This biological variability influences the high standard error of the regression (SE) of Hunter $a$ value, $b$-value and $\mathrm{TCD}_{\mathrm{H}}$ (Table 2$)$. This effect influenced negatively the correlation coefficients between the predicted and the experimental data.

Table 1

Estimated kinetic parameters for the degradation of chlorophyll in frozen stored green beans

\begin{tabular}{llllll}
\hline Chlorophyll & $E_{\mathrm{a}}[\mathrm{kJ} / \mathrm{mol}]$ & $k_{-15^{\circ} \mathrm{C} \times 10^{-2}\left[\text { days }^{-1}\right]}$ & $C_{0} \times 10^{-2}[\mathrm{mg} / \mathrm{g}]$ & $\mathrm{SE}^{\mathrm{a}} \times 10^{-3}[\mathrm{mg} / \mathrm{g}]$ & Corr. coeff. $^{\mathrm{b}}$ \\
\hline a & $48.730 \pm 1.273$ & $4.793 \pm 0.001$ & $4.559 \pm 0.063$ & 4.607 & 0.9961 \\
& $38.280^{\mathrm{c}}$ & $4793^{\mathrm{c}}$ & $72.365^{\mathrm{c}}$ & - & - \\
$\mathrm{b}$ & $49.595 \pm 1.938$ & $4.795 \pm 0.002$ & $2.572 \pm 0.096$ & 6.995 & 0.8302 \\
& $25.591^{\mathrm{c}}$ & $2397.5^{\mathrm{c}}$ & $26.792^{\mathrm{c}}$ & - & -
\end{tabular}

\footnotetext{
a Regression standard error.

b Correlation coefficient between model predicted and experimental data.

c Studentised effect, where $t_{(1-\alpha / 2 ; \mathrm{df})}=2.000$.
} 
(a)



(c)

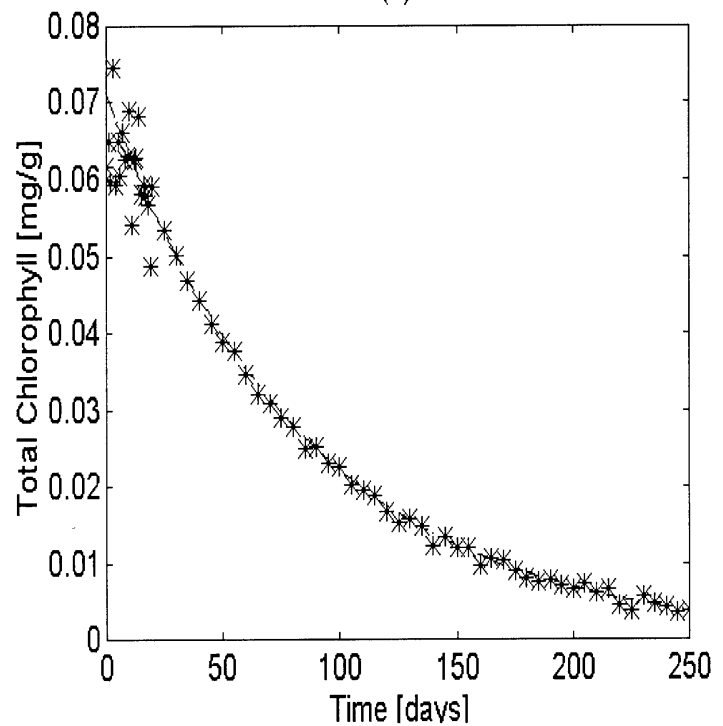

(b)
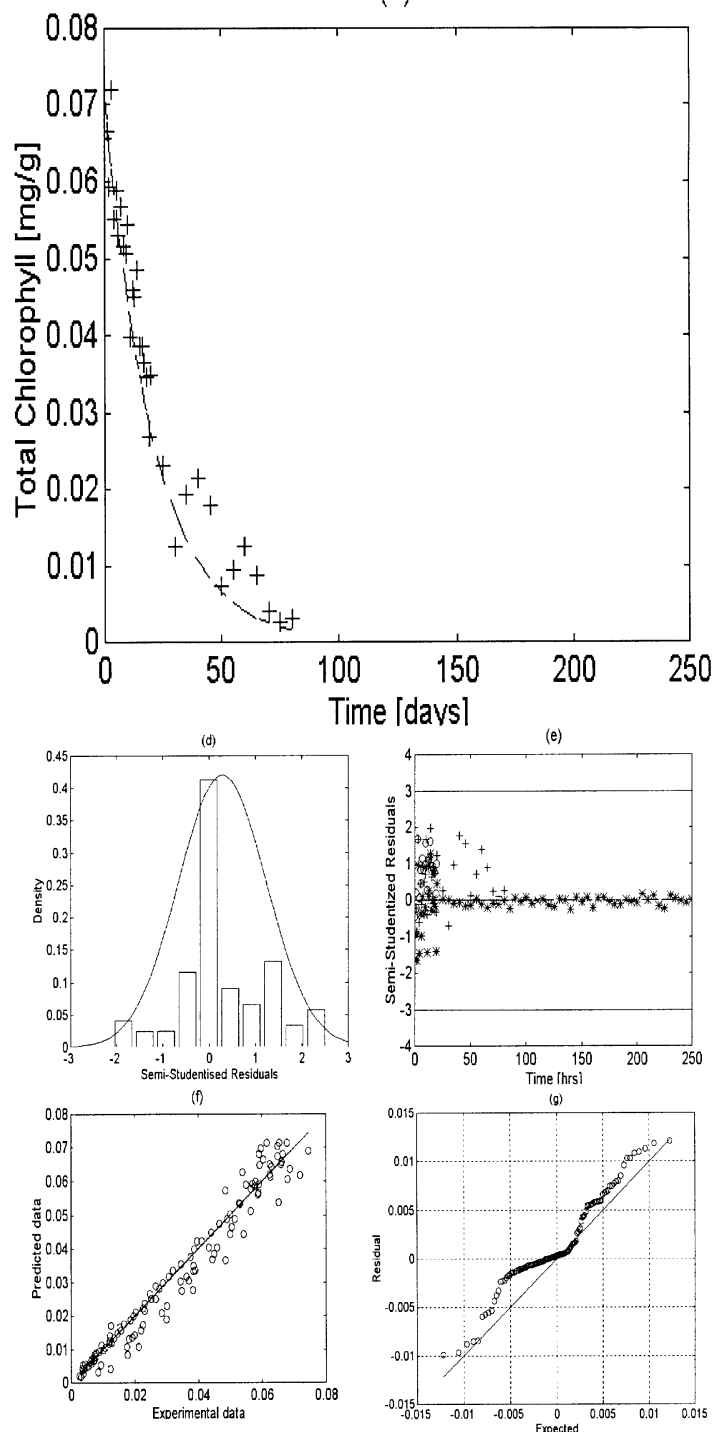

Fig. 1. Total chlorophyll degradation kinetics of green beans during frozen storage at: $(\mathrm{a})-7{ }^{\circ} \mathrm{C}(\mathrm{O}),(\mathrm{b})-15^{\circ} \mathrm{C}(+),(\mathrm{c})-30^{\circ} \mathrm{C}(*)$, (d) density plot of semi studentised residuals, (e) predicted vs experimental plot and (g) normal probability plot of residuals.

The $a$-value increased along storage time from an initial value of -11.93 until an equilibrium value of -6.33 . Therefore, this coordinate moved into less green regions of the Hunter Lab colour space. Other authors have also reported this kind of behaviour in the $a$-value, due to the chlorophyll's pheophytisation [11]. It is possible to observe in Table 2, that kinetic parameters exhibit very low variation. Furthermore, as their studentised effect is very significant, it is possible to conclude that the first order reversible kinetics is a valid model to describe colour changes. Temperature is also a very significant factor in colour retention. Not only the $a$ co-ordinate kinetics shows a high activation energy, but its studentised effect is very significant (Table 2). The high sensitivity to storage temperature assures that green colour can be stabilised if low temperatures are used during frozen storage. However, the $a$-value is also very sensitive to higher storage temperatures and temperature fluctuations. Similar results were obtained for the $\mathrm{TCD}_{\mathrm{H}}$ value.

The $b$ co-ordinate exhibits a faster degradation rate, decreasing from an initial value of $13.10 \pm 0.12$ until 
(a)

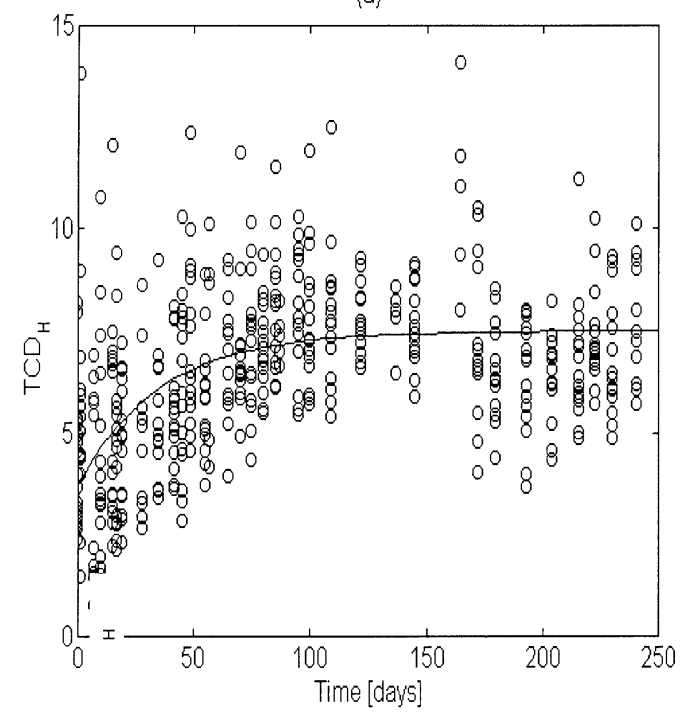

(c)

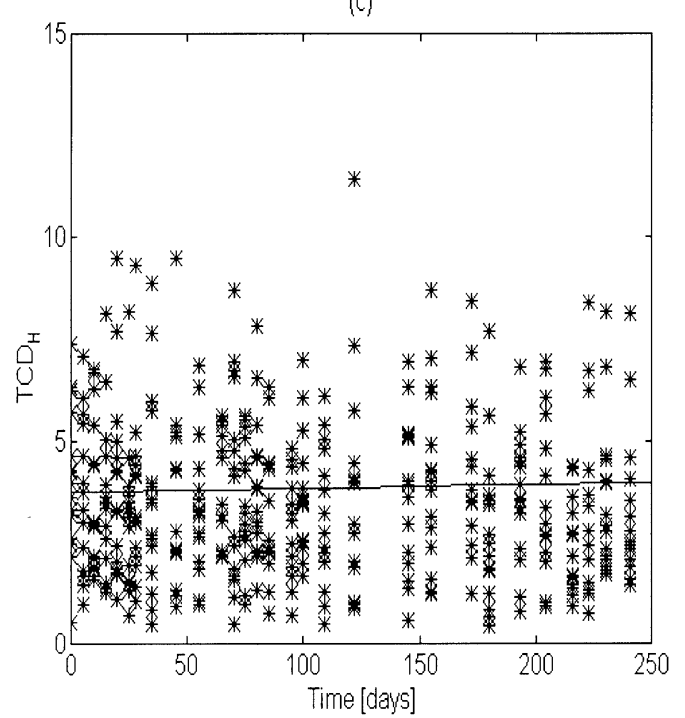

(b)
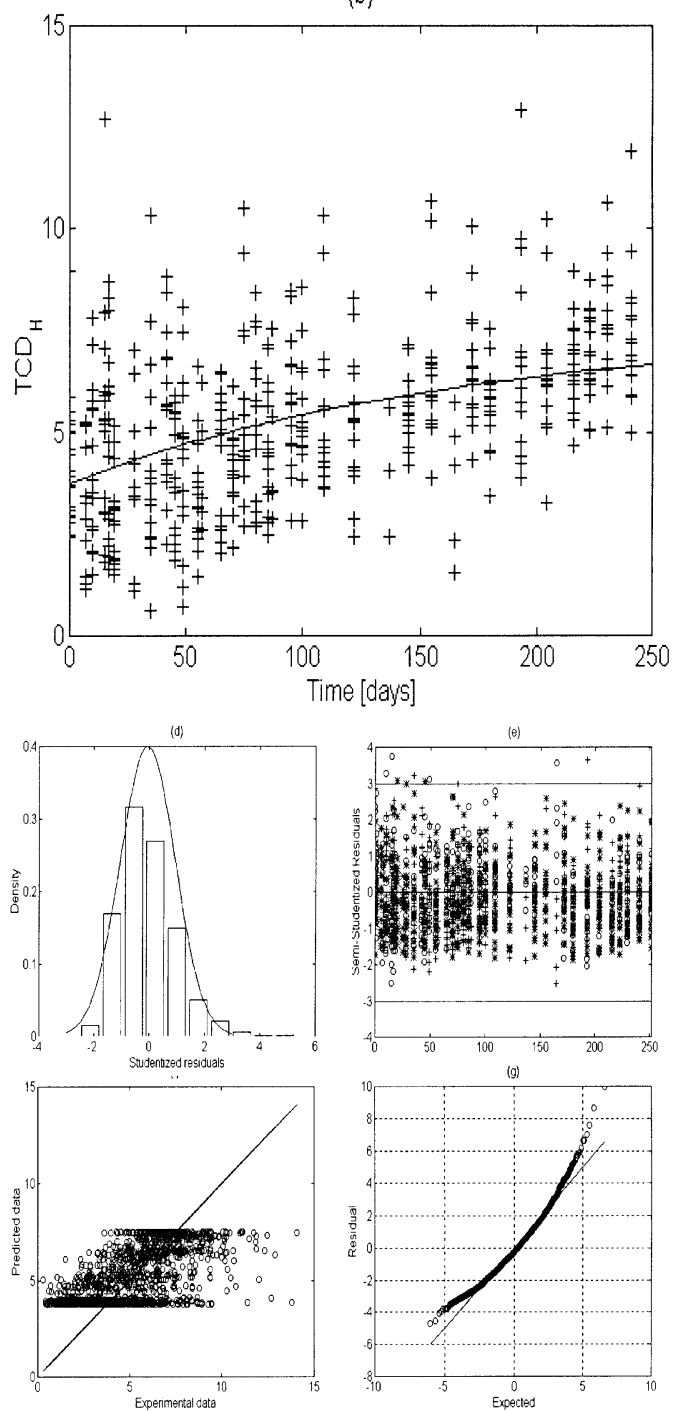

Fig. 2. Hunter total colour difference $\left(\mathrm{TCD}_{\mathrm{H}}\right)$ change kinetics of green beans during frozen storage: (a), (b) and (c) are the fitted and experimental values at $-7(\bigcirc),-15(+)$ and $-30{ }^{\circ} \mathrm{C}(*)$ respectively; (d) density plot of semi studentised residuals, (e) predicted vs experimental plot and $(\mathrm{g})$ normal probability plot of residuals.

$10.10 \pm 0.07$. However, it has a lower sensitivity to the storage temperature, due to a lower activation energy (Table 2). The equilibrium $b$-value is attained very rapidly for the three storage temperatures, when compared to the $a$ coordinate. This effect is particularly important at the storage temperatures of -7 and $-15^{\circ} \mathrm{C}$, where equilibrium values are attained during the first 100 and 200 days of storage, respectively. As for the $a$-value, the $b$ co-ordinate exhibits very high studentised effects in all kinetic parameters, assuring the applicability of the first order reversible model with Arrhenius law to describe the evolution of this colour coordinate during storage.

The $\mathrm{TCD}_{\mathrm{H}}$ values increased from an initial value of $3.74 \pm 0.10$ until an equilibrium value of $7.49 \pm 0.12$. The high activation energy and a similar kinetic rate at the reference temperature of $-15^{\circ} \mathrm{C}$ to the $a$ coordinate, further the high studentised effects (Table 2), allow us to reach to the same conclusions as for the $a$-value. As 
Table 2

Estimated kinetic parameters for the colour changes in frozen stored green beans

\begin{tabular}{lllllll}
\hline Colour parameter & $E_{\mathrm{a}}[\mathrm{kJ} / \mathrm{mol}]$ & $k_{-15^{\circ} \mathrm{C} \times 10^{-3}\left[\text { days }^{-1}\right]}$ & $C_{0}$ & $C_{\mathrm{eq}}$ & $S E^{\mathrm{a}}$ & Corr. coeff. $^{\mathrm{b}}$ \\
\hline$a$ & $103.053 \pm 0.072$ & $6.600 \pm 0.000$ & $-11.931 \pm 0.072$ & $-6.329 \pm 0.083$ & 1.389 & 0.8388 \\
& $1431.292^{\mathrm{c}}$ & inf $^{\mathrm{c}}$ & $165.708^{\mathrm{c}}$ & $76.253^{\mathrm{c}}$ & - & - \\
$b$ & $55.329 \pm 1.785$ & $22.189 \pm 0.349$ & $13.099 \pm 0.117$ & $10.101 \pm 0.072$ & 1.557 & 0.6871 \\
& $30.997^{\mathrm{c}}$ & $63.579^{\mathrm{c}}$ & $111.957^{\mathrm{c}}$ & $140.292^{\mathrm{c}}$ & - & - \\
$\mathrm{TCD}_{\mathrm{H}}$ & $106.272 \pm 1.049$ & $5.999 \pm 0.000$ & $3.745 \pm 0.095$ & $7.486 \pm 0.117$ & 1.872 & 0.6145 \\
& $101.308^{\mathrm{c}}$ & inf $^{\mathrm{c}}$ & $39.421^{\mathrm{c}}$ & $63.983^{\mathrm{c}}$ & - & - \\
\hline
\end{tabular}

a Regression standard error.

b Correlation coefficient between model predicted and experimental data.

c Studentised effect, where $t_{(1-\alpha / 2 ; \mathrm{df})}=1.960$.

expected, $\mathrm{TCD}_{\mathrm{H}}$ values are mostly influenced by the $a$ co-ordinate. However, both Hunter $a$ and $b$ co-ordinates have a significant effect on $\mathrm{TCD}_{\mathrm{H}}$ values.

\subsection{Colour losses and chlorophyll degradation}

Although colour and chlorophyll losses are well correlated, it is possible to observe in Fig. 3, that there is not a linear correspondence between $\mathrm{TCD}_{\mathrm{H}}$ and total chlorophyll losses for the three studied temperatures. This effect was also observed during frozen storage of kiwi pulp by Venning et al. in 1989 [37], where until $45 \%$ of the chlorophyll is lost, no colour difference was detected. It can also be observed in Fig. 3 that different $\mathrm{TCD}_{\mathrm{H}}$ values were obtained for the same total chlor-



Fig. 3. Total chlorophyll content as a function of the Hunter total colour difference $\left(\mathrm{TCD}_{\mathrm{H}}\right)$ at $-7,-15$ and $-30{ }^{\circ} \mathrm{C}$. ophyll content at the three studied storage temperatures. This result was particularly unexpected. If pheophytisation is the main chlorophyll's degradation pathway, then $\mathrm{TCD}_{\mathrm{H}}$ value would correspond to a unique chlorophyll content, whatever the storage temperature. Another discrepancy was obtained in terms of the Ahrrenius activation energy (Tables 1 and 2). The higher activation energy of $\mathrm{TCD}_{\mathrm{H}}$ and $a$-value results in better colour stability than chlorophyll retention, as lower and stable storage temperatures are achieved. Our results show that colour stability of green beans is higher than that of chlorophyll at the three studied storage temperatures. Such discrepancies, between colour and chlorophyll reaction rates, are attributed in most cases to the measurement of colour to be quantitatively different from the measurement of chlorophyll mass [37]. However, the huge difference in the activation energies raises the question if pheophytisation is the main pathway of chlorophyll's degradation at all storage temperatures. Already in 1937, Cambell (referred by Dietrich 1956 [1]) observed undesirable colour changes in frozen peas only above $0{ }^{\circ} \mathrm{F}\left(-18{ }^{\circ} \mathrm{C}\right)$, attributing the main cause of colour loss to the mechanism of pheophytisation above this temperature. On the contrary, other authors reported that chlorophyll's content could be stabilised below storage temperatures of -18 and $-20{ }^{\circ} \mathrm{C}$ for frozen kiwi and leafy parsley $[37,38]$.

Colour can be stabilised due to the increase of the concentration of metal ions, such as copper, in the unfrozen phase [9]. These ions compete with hydrogen, in a parallel reaction, for the replacement of the centre magnesium. The formation of compounds like cupric chlorophyll or cupric chlorophyllide stabilise colour. The same effect can be achieved with zinc complexes (e.g. bright green colour in canned peas), since bivalent metal ions are generally present at levels of $0.7-0.2 \mathrm{mg} /$ $100 \mathrm{~g}$ of green beans. Therefore, the existing copper and zinc in the unfrozen phase, which may have been released from denatured enzymes during blanching, will 
compete with $\mathrm{H}^{+}$and free magnesium for the tetrapyrrole centre. Lower storage temperatures may increase this effect due to continuous concentration of electrolytes and $\mathrm{pH}$ stabilisation (due to dibasic salts eutectic cristallisation).

\section{Conclusions}

Chlorophyll and colour loss at high storage temperatures are mainly attributed to pheophytisation. At lower storage temperatures, colour is stabilised probably by the formation of metal-chlorophyll compounds. Therefore, although green beans colour and chlorophyll content deteriorate during frozen storage, and chlorophyll content is related to the initial vivid green colour, chlorophyll content does not give a reliable prediction of colour retention.

The obtained kinetic models can accurately describe the colour and chlorophyll losses during frozen storage, and the temperature dependency of the reaction rate followed the Arrhenius model.

We feel that there is not enough experimental evidence to give a conclusive explanation for the described discrepancies. Therefore, the relationship between chlorophyll degradation and colour changes during frozen storage needs further investigation.

\section{Acknowledgements}

R.C. Martins gratefully acknowledges his $\mathrm{PhD}$ grant (PRAXIS XXI BD/18541/98) to the Fundação para a Ciência e Tecnologia (FCT).

\section{References}

[1] Dietrich WC, Lindquist FE, Miers JC, Bohart GS, Newman HJ, Talburn WF. The time temperature tolerance of frozen foods IV. Objective tests to measure adverse changes in frozen vegetables. Food Technology 1956;10:109-13.

[2] Boogs MM, Dietrich WC, Nutting MD, Olson RL, Lindquist FE, Bohart GS, et al. Time-temperature tolerance of frozen foods XXI. Frozen peas. Food Technology 1960; 14:181-5.

[3] Dietrich WC, Mildred MB, Nutting MD, Weinstein NE. Time temperature tolerance of frozen foods. XXIII. Quality changes in frozen spinach. Food Technology 1960;14:522-7.

[4] Dietrich WC, Bohart GS, Neumann HJ, Morris HJ. Time temperature tolerance of frozen foods XXI. Quality retention of frozen green snap beans in retail packages. Food Technology 1959;13:136-45.

[5] Dietrich WC, Boogs MM, Nutting MD, Weinstein NE. Time temperature tolerance of frozen foods XXIV. Quality changes in cauliflower. Food Technology 1960;16:123-8.
[6] Heaton JW, Lencki RW, Maragoni AG. Kinetic model for chlorophyll degradation in green tissue. Journal of Agricultural Food Chemistry 1996;44:399-402.

[7] Schwartz SJ, Von Elbe JH. Kinetics of chlorophyll degradation to pyropheophytin in vegetables. Journal of Food Science 1983;48:1303-6.

[8] Schwartz SJ, Loranzo TV. Chlorophyll stability during continuous aseptic processing and storage. Journal of Food Science 1991;56:4 1059-62.

[9] Schweimer S. Source book of food Enzymology. Wesport, CT: AVI Publishing, 1984.

[10] Shin S, Bhowmik SR. Thermal kinetics of colour changes in pea puree. Journal of Food Engineering 1995;32:35164.

[11] Steet JA, Tong CH. Degradation kinetics of green color and chlorophyll's in peas by colorimetry and HPLC. Journal of Food Science 1996;61:924-7 931.

[12] Clydesdale FM, Francis FJ. Pigments. Principles of food science-Part I-food chemistry. New York: Marcel Dekker, 1976. p. 386-413.

[13] Fennema OR, Powrie WD, Marth EH. Low-temperature preservation of foods and living matter. New York: Marcel Dekker, 1973.

[14] Ehart MS. Effect of storage and other variables on composition of frozen broccoli. Food Technology 1970;24: 1009-32.

[15] Rafael SD. Effect of storage time - food processing plants and marketing conditions on the quality of some frozen vegetables. $\mathrm{PhD}$ thesis, University of Alexandria, Egypt, 1992.

[16] Villota R, Hawkes JG. Reaction kinetics in food systems. In: Handbook of food engineering. New York: Marcel Dekker, 1992: p. 39-144.

[17] Abbott JA. Quality measurement of fruits and vegetables. Postharvest Biology and Technology 1999;15:207-25.

[18] Kramer A. Use of colour measurement in quality control of foods. Food Technology 1976;30:62-4,66,68,70-71.

[19] Francis FJ. Quality as influenced by colour. Food Quality and Preference 1995;6:149-55.

[20] DrLange. Colour review. DrLange application report No.8e. USA; 1994.

[21] Poynton C. A guide tour of colour space. Proceedings of the SMPTE advanced television and electronic imaging conference 1995. p. 167-80.

[22] Drlange. Fundamentals of colorimetry-appliction report No. 10e; 1999.

[23] Poynton C. Frequently asked questions about colour. www.inforamp.net/ p poynton/ColorFAQ.pdf $\quad[25 / 01 /$ 2000], 1999.

[24] Minolta. Precise colour communication: colour control from feeling to instrumentation, Minolta Report Japan, 1994.

[25] Silva FM, Silva CLM. Colour changes in thermally processed cupuaçu (Theobroma grandiflorum) puree: critical times and kinetic modelling. International Journal of Food Science and Technology 1999;34:87-94.

[26] Ávila IMLB, Silva CLM. Modelling kinetics of thermal degradation of colour in peach puree. Journal of Food Engineering 1999;39:161-6.

[27] Labuza TP. Shelf-life dating of foods. Wesport, CT: Food and Nutrition Press, 1982. 
[28] Armfield Ltd. Instruction manual-blast and fluid bed freezer FT36; issue 7; Hampshire, England, 1995.

[29] Barth MM, Kerbel EL, Perry AK, Schmidt SJ. Modified atmosphere packaging affects ascorbic acid, enzyme activity and market quality of Broccoli. Journal of Food Science 1993;58:140-3.

[30] Hemeda HM, Kleind BP. Effects of naturally occurring antioxidants on peroxidase activity of vegetables extracts. Journal of Food Science 1990;33:58-61.

[31] Eheart MS, Gott C. Chlorophyll, ascorbic acid and pH changes in green vegetables cooked by stir-fry, microwave, and conventional methods and a comparison of chlorophyll methods. Food Technology 1965;5:185-9.

[32] Vernon LP. Spectrophotometric determination of chlorophylls and pheophytins in plant extracts. Analytical Chemistry 1960;32:1144-50.
[33] Arabshahi A, Lund DB. Considerations in calculating kinetic parameters from experimental data. Journal of Food Process and Engineering 1985;7:239-51.

[34] Neter J, Kutner MH, Nachtsheine CJ, Wasserman W. Applied linear statistical models. Chicago: IRWIN, 1996.

[35] Bates DM, Watts DG. Non-linear regression analysis and its applications. New York: John Wiley \& Sons, 1988.

[36] Box GEP, Hunter WG, Hunter JS. Statistics for experimenters. New York: John Wiley \& Sons, 1978.

[37] Venning JA, Burns DJW, Hoskin KM, Nguyen T, Stee, MGH. Factors influencing the stability of frozen kiwifruit pulp. Journal of Food Science 1989; 54: 396-400, 404.

[38] Lisiewska Z, Kmiecik W. Effect of freezing and storage on quality factors in Hamburg and leafy parsley. FoodChemistry 1997;60:633-7. 